\title{
MONITORING PERIKANAN LEMURU DI PERAIRAN SELAT BALI
}

\author{
Monitoring Lemuru Fisheries On Bali Strait Waters \\ Satria Wiratama Nugraha, Abdul Ghofar*, Suradi Wijaya S \\ *Program Studi Manajemen Sumberdaya Perairan \\ Departemen Sumberdaya Akuatik Fakultas Perikanan dan Ilmu Kelautan Universitas Diponegoro \\ Jl. Prof. Soedharto, SH Semarang \\ Email : satriawn95@gmail.com
}

\begin{abstract}
ABSTRAK
Perairan Selat Bali merupakan perairan yang berada diantara Pulau Jawa dan Pulau Bali. Perairan ini memiliki sumber daya perikanan pelagis kecil yang melimpah, terutama ikan lemuru. Pendaratan ikan lemuru di Perairan Selat Bali berpusat di UPT PP (Unit Pelaksana Teknis Pelabuhan Perikanan) Muncar, Kabupaten Banyuwangi. Penelitian ini bertujuan untuk mengetahui jumlah dan ukuran kapal, serta alat bantu penangkapan, Catch Per Unit Effort penangkapan, dan pengelolaan perikanan lemuru di perairan Selat Bali. Penelitian ini dilaksanakan pada tanggal 20 Maret - 21 Mei 2017. Metode yang digunakan adalah observatif. Data yang digunakan adalah data produksi ikan lemuru di UPT PP Muncar dan PPN (Pelabuhan Perikanan Nusantara) Pengambengan dari tahun 1980-2016, data kapal dan alat tangkap dari tahun 2010-2016. Berdasarkan data tersebut, dilakukan perhitungan Maximum Sustainable Yield (MSY) dengan menggunakan model surplus produksi Gordon Scheafer. Jumlah kapal yang digunakan untuk penangkapan ikan lemuru saat ini adalah 326 armada dengan ukuran 10-30 GT (gross ton) yang didominasi oleh kapal ukuran 29/30 GT . Jumlah kapal 10 - 30 GT di Muncar 190 unit, sedangkan di Pengambengan 136 unit. Alat tangkap yang digunakan adalah purse seine dengan jumlah 326 dengan panjang 180 depa ( \pm 338 meter) dan mesh size 0,5 inchi, dengan rata - rata kekuatan mesin $120-240$ PK, lampu 700 - 1200 watt sebanyak 5 - 12 unit / kapal. Nilai CPUE terendah adalah 0,378 ton/trip, dengan rata - rata 3,43 ton/ trip. Nilai $M S Y$ yang didapatkan sebesar 25.107,32 ton/tahun, sementara nilai JTB (Jumlah Tangkapan Diperbolehkan) adalah 20.085,86 ton per tahun. Perairan Selat Bali berada dalam otonomi Pemerintah Provinsi Jawa Timur, dan Provinsi Bali. Sehingga pada tahun 1977 dikeluarkan Surat Keputusan Bersama Gubernur Jawa Timur, dan Gubernur Bali, untuk mengatur sistem penangkapan ikan di Perairan Selat Bali. Surat Keputusan Bersama ini diperbarui beberapa kali, kemudian dikeluarkan Peraturan Menteri Kelautan Perikanan dan Kelautan Nomor 68 Tahun 2016 tentang Rencana Pengelolaan Perikanan Ikan Lemuru di Wilayah Pengelolaan Perikanan Republik Indonesia.
\end{abstract}

Kata Kunci : Sardinella lemuru, Ikan Lemuru, Monitoring, Selat Bali, PPP Muncar, PPN Pengambengan.

\section{ABSTRACT}

Bali Strait waters is a located between Java Island and Bali Island. This waters has a lot of pelagic fish resources, especially lemuru fish. Lemuru fisheries centered on UPT PP ( Unit Techic Implementers Fisheries Port) Muncar, Banyuwangi Region. This research goals are to knows the amount of boat and it size, total fishing gears, Catch Per Unit Effort lemuru fisheries on Bali Strait waters, and know the status of lemuru fishings. This research held on 20 Maret - 21 Mei 2017. The method of the research is observative. The data wich used is the data production of lemuru fishing on UPT PP Muncar and PPN (Archipelago Fisheries Port) Pengambengan on 1980 -2016, boats data and fishing gears on 2010 - 2016. Based on the data, calculating MSY using surplus production model by Gordon Scheafer. Total boats for lemuru fishes are 326 boats, wich sizes 10-30 GT (gross tonnage) and dominated by 29/30 GT. The boats 10 - 30 GT in Muncar 190 units, event on Pengambengan 136 units. Fishing gears using purse seine wich 326 units, width 180 depa ( \pm 338 meters) and mesh size 0,5 inchi, wich average powers 120 - 240 PK, lightning $700-1200$ watt $5-12$ units / boats. The value of lowest CPUE is 0,378 ton/trip, with average is 3,43 ton/trip. The value of MSY is 25.107,32 ton/year, and TAC (Total Allowable Catch) is 20.085,86 ton/year. Bali Strait waters under otonomy by East Java and Bali Government. So, in 1977 formed GRC (Government Regulatory Compliance) by East Java and Bali Government to ruled fisheries systems on Bali Strait waters. This GRC renew few times, and then formed Regulation by Minister of Marine and Fisheries number 68 year 2016 about Plans Management Fisheries of Lemuru Fish in Indonesia Region Management.

Keywords: Sardinella lemuru, Lemuru Fishes, Monitoring, Bali Strait, PPP Muncar, PPN Pengambengan. *Penulis penanggung jawab 


\section{PENDAhUluAN}

Salah satu potensi kelautan dan perikanan Indonesia adalah perikanan tangkap. Indonesia memiliki potensi sumber daya perikanan yang sangat besar baik dari segi kuantitas maupun keanekaragamannya. Potensi lestari (maximum sustainable yield/MSY) menurut Komisi Nasional Pengkajian Stok Sumber Daya Ikan Laut (KNPSSDIL) tahun 2014, sumber daya perikanan tangkap diperkirakan sebesar 6,4 juta ton per tahun. Bahkan, setelah pemberantasan IUU Fishing oleh Kementrian Kelautan dan Perikanan, di perkirakan MSY pada tahun 2016 meningkat menjadi kisaran 9 juta ton per tahun. Hal ini merupakan sebuah kemajuan dalam industri kelautan dan perikanan Indonesia (Pudjiastuti, 2016).

Indonesia memiliki potensi perikanan tangkap yang sangat baik. Contohnya adalah ikan lemuru (Sardinella $s p$ ) yang di tangkap di perairan Selat Bali. Sumber daya perikanan lemuru merupakan sumber daya perikanan yang paling dominan dan bernilai ekonomis di Selat Bali, sehingga komoditi tersebut paling banyak dieksploitasi oleh nelayan yang bermukim di sekitar Selat Bali. Selain itu perikanan lemuru mempunyai peranan yang cukup penting bagi kehidupan masyarakat setempat. Manfaat lain dari usaha perikanan lemuru adalah sebagai sumber pendapatan daerah, penunjang industri lokal, dan menambah penyediaan lapangan kerja baik di laut maupun didarat.

Perikanan lemuru di perairan Selat Bali berkembang sangat pesat sejak diperkenalkannya alat tangkap pukat cincin oleh peneliti Lembaga Penelitian Perikanan Laut (LPPL) yang menjadi BPPL pada tahun 1972. Sumber daya ikan pelagis kecil di perairan Selat Bali terdiri dari berbagai jenis ikan seperti lemuru, layang, kembung, tembang dan selar, tetapi yang dominan adalah ikan lemuru (Sardinella $s p$ ).

Hasil tangkapan ikan lemuru memberi kontribusi yang sangat besar terhadap total hasil tangkapan pukat cincin di perairan Selat Bali. Pada tahun 1998 ikan lemuru memberikan kontribusi sebesar 98\% terhadap total hasil tangkapan armada pukat cincin di Selat Bali. Sedangkan pada tahun 2007 memberikan kontribusi 89\% dan 2016 menjadi 71\% terhadap total hasil tangkapan. Menurut Arif et al., (2013), pesatnya perkembangan perikanan lemuru ini didukung pula oleh adanya pabrik-pabrik pengolahan, seperti pengalengan ikan, pemindangan, tepung ikan, serta industri jasa penyimpanan ikan (cold storage) yang terdapat di sekitar tempat pendaratan utama, yaitu di Muncar dan Pengambengan.

\section{MATERI DAN METODE}

\section{Materi Penelitian}

Materi yang digunakan dalam penelitian yaitu data penangkapan ikan lemuru tahun 1980-2016 di PPP

Muncar dan PPN Pengambengan.

\section{Metode Sampling dan Pengumpulan Data}

Jenis data yang dikumpulkan adalah data kuantitatif primer, dan sekunder. Data kuantitatif yang dikumpulkan adalah data produksi, panjang ikan, GT kapal, dimensi alat tangkap, serta alat tangkap tambahan yang digunakan oleh nelayan untuk menangkap ikan lemuru.

\section{Sampel Kapal}

Menurut Umar (2004), rumus untuk menghitung jumlah sampel yang dijadikan responden adalah sebagai berikut:

$\mathrm{n}=\mathrm{N} \mathrm{Z}^{2} \mathrm{P}^{(1-\mathrm{P})} \mathrm{N} \mathrm{d}^{2}+\mathrm{Z}^{2} \mathrm{P}^{(1-\mathrm{P})}$

Keterangan:

$\mathrm{n}=$ Banyaknya sampel yang diambil

$\mathrm{N}=$ Jumlah populasi unit purse seine

$\mathrm{d}=$ Kesalahan maksimal yang dapat diterima $(0,1)$

$\mathrm{Z}=$ Normal variabel $(1,96)$

$\mathrm{P}=$ Percent variance $(0,05)$

Jumlah populasi alat tangkap Purse Seine 10-30 GT sebesar 125 unit, sehingga dengan menggunakan rumus tersebut diperoleh jumlah sampel 16 unit alat tangkap Purse Seine. Metode pengumpulan data dilakukan dengan cara observasi, wawancara, dokumentasi dan studi pustaka. Jenis data yang dikumpulkan berupa data primer dan data sekunder. Data primer meliputi jumlah hasil tangkapan per trip (Ton), ukuran alat tangkap atau ukuran jaring $\left(\mathrm{m}^{2}\right)$, mesh size alat tangkap, ukuran kapal yang digunakan (GT), kekuatan mesin yang digunakan, dan alat bantu cahaya terkait daya lampu yang digunakan (Watt) (Pratama et.al, 2016).

\section{Analisis data}

Data sekunder yang didapatkan dilakukan analisis untuk mendapatkan nilai CPUE dan MSY dengan menggunakan Model Surplus Produksi Scheafer :

1. Memasukkan data produksi total tahunan ke dalam aplikasi Microsoft excel

2. Membuat grafik dari data tersebut

3. Menambahkan trendline dari produksi ikan

4. Memasukkan data total upaya ( $\mathrm{f}$ ) dalam satu tahun kedalam aplikasi pengolah data

5. Menghitung persamaan regresi antara $C P U E$ tahunan dengan total effort tahunan

6. Membuat grafik trendline CPUE dengan effort

7. Memasukkan rumus intercept dari data $C P U E$ dan trip, untuk mendapatkan nilai a

8. .Memasukkan rumus slope dari data $C P U E$ dan trip, untuk mendapatkan nilai b

\footnotetext{
${ }^{\circledR}$ Copyright by Management of Aquatic Resources (MAQUARES)
} 
9. $\quad$ Menghitung $M S Y$ dengan Model Surplus Produksi Gordon Scheafer

Hitung foptimum $=\left|-\frac{a}{2 b}\right|$

\section{HASIL DAN PEMBAHASAN}

\section{Hasil Penelitian}

Penelitian dilakukan di PPP Muncar dan PPN Pengambengan pada tanggal 20 Maret - 21 Mei 2017. Berikut peta lokasi penelitian :

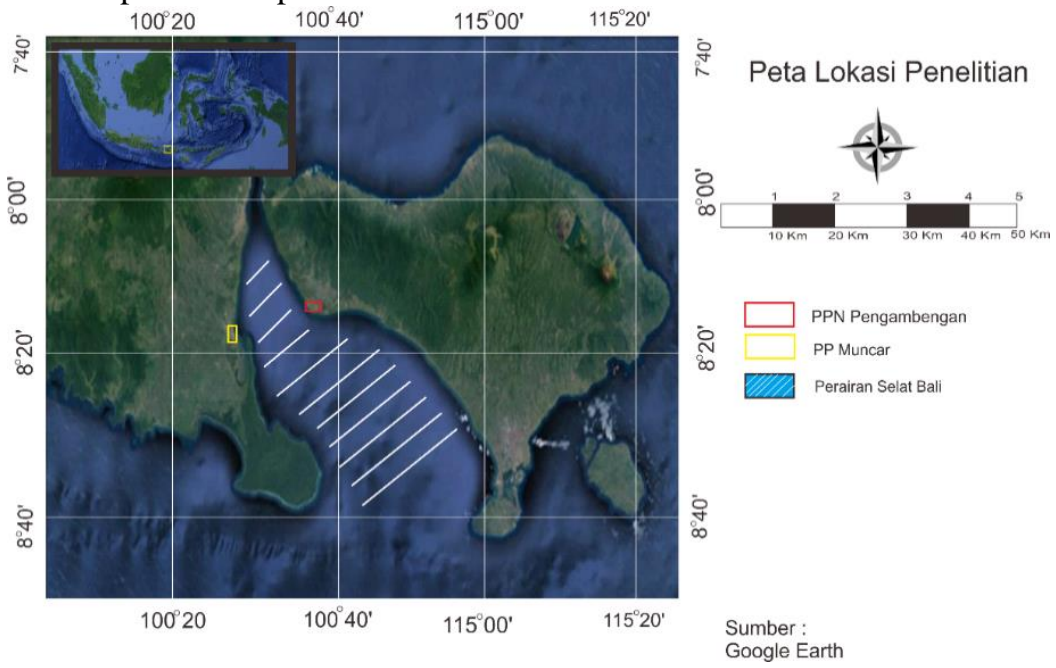

Gambar 1. Peta Lokasi Penelitian

Saat penelitian dilakukan, sedang terjadi masa paceklik yang menyebabkan banyak cold storage serta pabrik pengolahan dan pengalengan ikan lemuru yang mangkrak. Berdasarkan data dari PPP Muncar Cold storage di sekitar PPP Muncar berjumlah 41 unit. Namun, saat dilakukan penelitian, 90\% cold storage tersebut tidak beroperasi. Data ini didapatkan dari hasil wawancara dengan karyawan di 10 tempat cold storage. Sementara untuk industri pengolahan dan pengalengan ikan lemuru terdapat 12 unit. Tiga pabrik yang masih beroperasi selama masa paceklik berlangsung mengimpor ikan lemuru dari India dan New Zealand.

Sardinella lemuru merupakan komoditas utama di perairan Selat Bali. Pada saat musim ikan lemuru nelayan biasa mendaratkan hasil tangkapannya di PPP Muncar ataupun PPN Pengambengan. Rata-rata produksi ikan lemuru di perairan Selat Bali 10 tahun terakhir adalah 70,6\% dari total tangkapan di perairan Selat Bali, berikut gambar dari presentase produksi ikan lemuru dari total produksi :

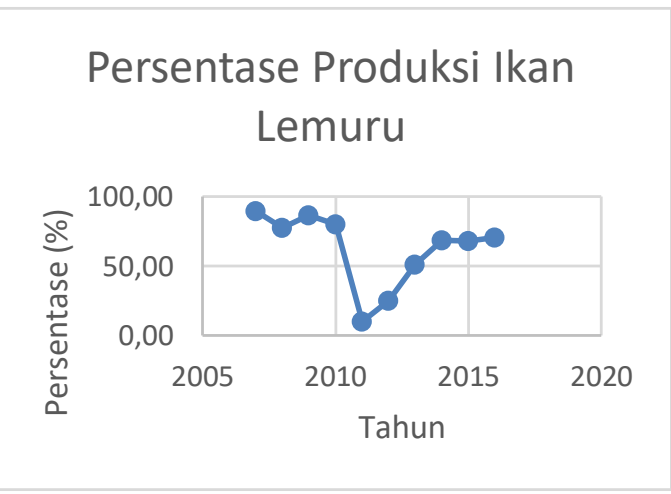

Gambar 2. Persentase Produksi Ikan Lemuru

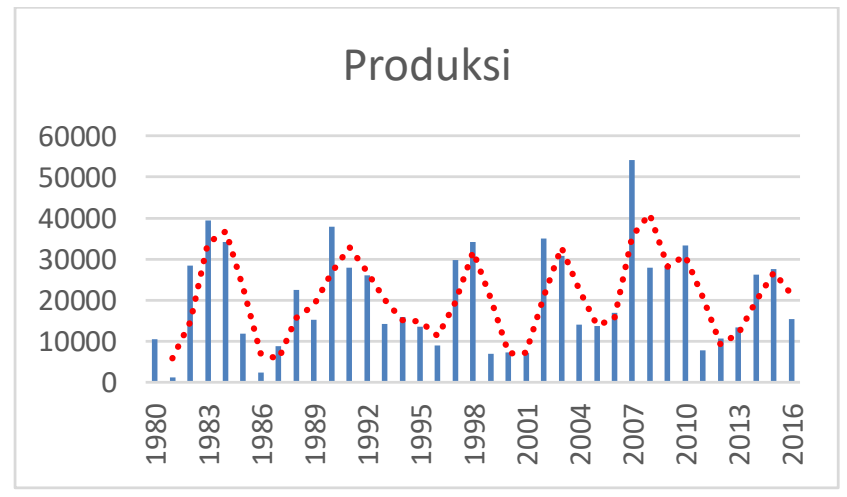

Gambar 3. Produksi Ikan Lemuru di Perairan Selat Bali

Berdasarkan Gambar 2 tersebut dapat dilihat dinamika penangkapan ikan lemuru di perairan Selat Bali. Presentase hasil tangkapan ikan lemuru didapatkan dengan cara mempresentasekan hasil tangkapan dari total 
tangkapan di PPP Muncar dan PPN Pengambengan. Pada tahun 2007 merupakan presentase produksi tertinggi yaitu $89,56 \%$. Sedangkan presentase produksi terendah terjadi pada tahun 2011 yaitu $9,99 \%$.

Produksi ikan lemuru dari tahun 1980 - 2016 sangat fluktuatif, hal ini disebabkan karena penangkapan ikan lemuru dipengaruhi oleh berbagai faktor. Produksi ikan lemuru dapat dilihat pada gambar 3. Berdasarkan data pada grafik tersebut, dapat diketahui produksi ikan lemuru di Selat Bali sangat dinamis. Produksi ikan lemuru di perairan Selat Bali mengalami penurunan yang sangat drastis pada tahun 1980 - 1981 , 1984 - 1985, 1992 - 1993, 2002 - 2003, 2010 - 2011. Dalam kurun waktu tertentu produksi mencapai puncaknya dan kemudian akan menurun, dan meningkat kembali pada tahun berikutnya.

Alat tangkap yang digunakan dalam penangkapan ikan lemuru dalah purse seine. Purse seine untuk kapal yang berukuran 10-30 GT adalah 0,5 inchi, dengan panjang jaring \pm 338 meter dengan kedalaman 30 meter . Sementara untuk kapal yang berukuran 5-10 GT, 0,5 inchi, dengan panjang jaring \pm 56 meter dengan kedalaman 10 meter. Berikut jumlah Purse seine di PP Muncar dan PPN Pengambengan :

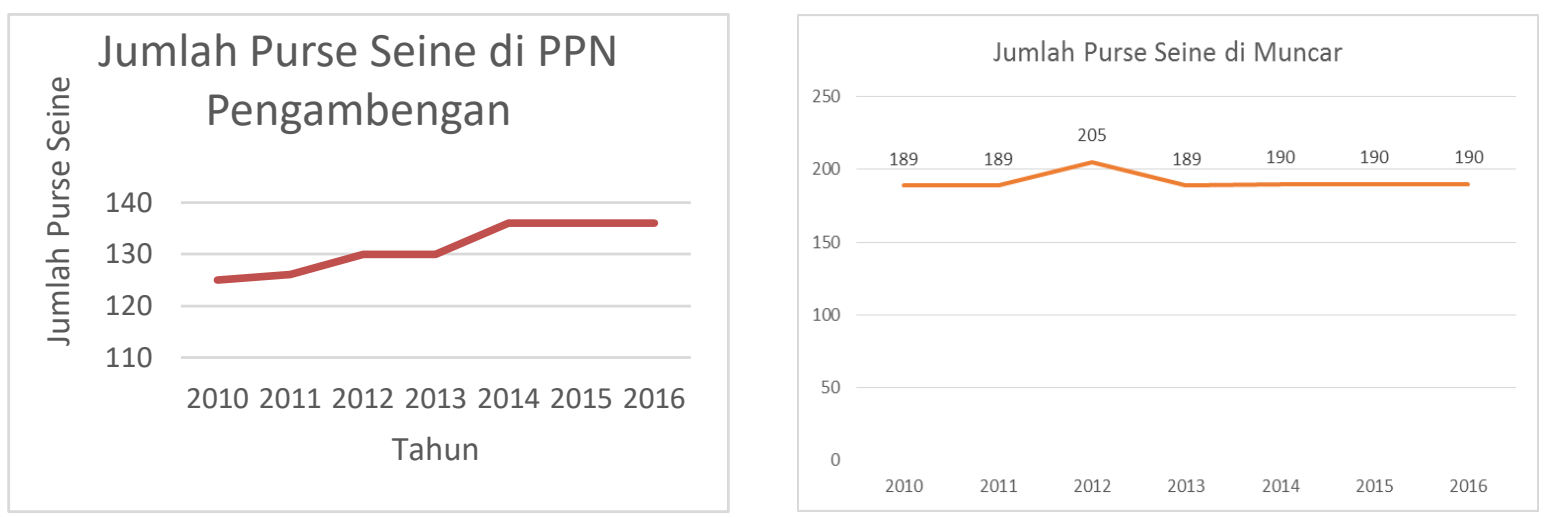

Gambar 4. Jumlah Purse seine di PPN Pengambengan. Gambar 5. Jumlah Purse siene di PPP Muncar.

Berdasarkan Gambar 4 tersebut dapat diketahui bahwa alat tangkap purse seine di PPN Pengambengan mengalami peningkatan jumlah dari tahun ke tahun. Mesh size dan panjang alat tangkap Purse seine untuk kapal yang berukuran 10-30 GT adalah 0,5 inchi, dengan panjang jaring adalah \pm 338 meter. Kapal berukuran 10-30 GT di dominasi kapal berukuran 29/30 GT.

Berdasarkan Gambar 5 tersebut dapat diketahui jumlah alat tangkap purse seine di Pelabuhan Muncar stabil dan tidak mengalami kenaikan ataupun penurunan jumlah yang signifikan. Armada pada kategori 10 - 30 GT di dominasi oleh kapal yang berukuran 29 / 30 GT. Sementara untuk ukuran dan dimensi kapal dapat dilihat dalam Tabel berikut :

\begin{tabular}{lllllll}
\hline NO & GT & P & L & D & Lampu & Mesin \\
\hline 1 & 29 & 18.75 & 5.45 & 1.64 & 9 & 7 \\
2 & 29 & 18.75 & 5.45 & 1.64 & 9 & 7 \\
3 & 29 & 18.75 & 5.45 & 1.64 & 12 & 7 \\
4 & 30 & 19.40 & 5.25 & 1.60 & 10 & 8 \\
5 & 30 & 19.40 & 5.25 & 1.60 & 12 & 8 \\
6 & 30 & 19.40 & 5.25 & 1.60 & 10 & 7 \\
7 & 30 & 19.40 & 5.25 & 1.60 & 8 & 7 \\
8 & 29 & 18.75 & 5.45 & 1.64 & 10 & 7 \\
9 & 29 & 18.75 & 5.45 & 1.64 & 8 & 7 \\
10 & 29 & 18.75 & 5.45 & 1.64 & 9 & 7 \\
11 & 30 & 19.40 & 5.25 & 1.60 & 8 & 7 \\
12 & 30 & 19.40 & 5.25 & 1.60 & 10 & 8 \\
13 & 30 & 19.40 & 5.25 & 1.60 & 8 & 8 \\
14 & 24 & 14.00 & 3.6 & 1.10 & 6 & 7 \\
15 & 24 & 14.00 & 3.6 & 1.10 & 6 & 7 \\
16 & 9 & 6.25 & 2.2 & 1.10 & 4 & 4 \\
17 & 9 & 6.25 & 2.2 & 1.10 & 4 & 4 \\
18 & 28 & 17.42 & 4.79 & 1.76 & 8 & 6 \\
19 & 28 & 17.42 & 4.79 & 1.76 & 8 & 6 \\
\hline
\end{tabular}

${ }^{\circledR}$ Copyright by Management of Aquatic Resources (MAQUARES) 
Berdasarkan Tabel 1 dapat diketahui kapal yang berukuran 10 - 30 GT memiliki dimensi panjang 16-20 x 4-6 x 2-2,5 meter. Umumnya menggunakan 4-8 Mesin pendorong dengan kekuatan 30 PK, sehingga total daya kapal 120-240 PK. Selain itu, kapal-kapal tersebut juga menggunakan alat bantu penangkapan berupa lampu sorot berdaya 400 watt sebanyak 5-12 unit. Untuk kapal yang berukuran 5-10 GT menggunakan 2-4 mesin, dengan kekuatan yang sama serta alat bantu lampu sebanyak 3-7 unit.

\section{Catch Per Unit Effort dan Maximum Sustainable Yield}

Catch Per Unit Effort merupakan hasil olahan data dari produksi/ trip per-tahun. Berdasarkan data yang diperoleh, maka dapat dibuat grafik Catch Per Unit Effort, dan Maximum Sustainable Yield dengan menggunakan model Gordon Scheafer seperti gambar 6 dan 7 :

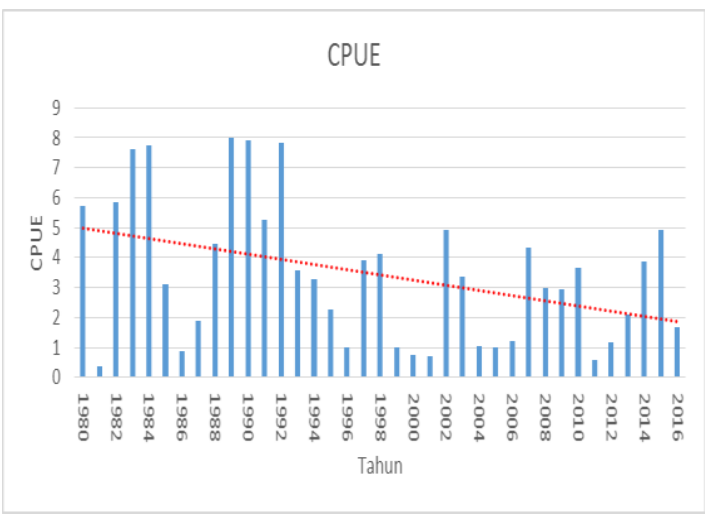

Gambar 6. CPUE Ikan Lemuru Tahun 1980-2016

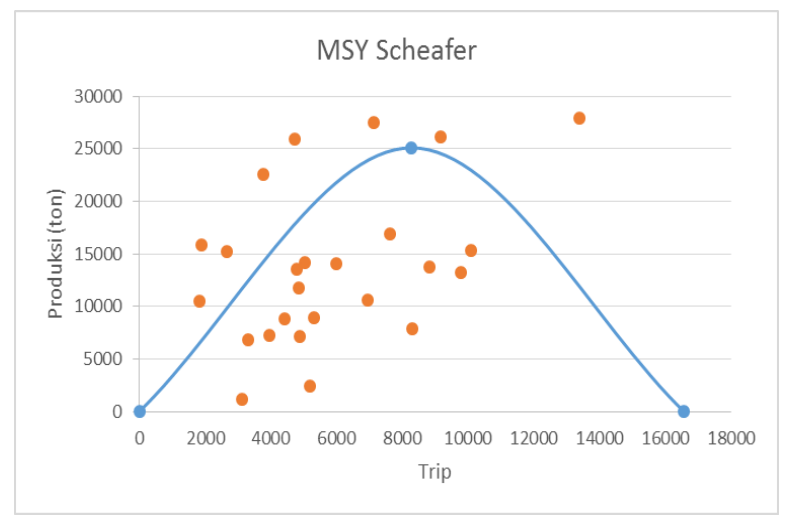

Gambar 7. MSY Model Scheafer

Berdasarkan Gambar 6 diketahui nilai CPUE ( catch per unit effort ) dari tahun 1980-2016. Nilai CPUE tertinggi didapatkan ketika tahun 1989 dengan nilai maksimum 8,009 dan nilai minimun terjadi pada tahun 1981 dengan nilai 0,378. Nilai CPUE menunjukkan tren yang menurun dari waktu ke waktu. Setelah mendapatkan nilai CPUE maka dapat dilakukan penghitugan nilai MSY. Nilai MSY yang didapatkan dari perhitungan tersebut dapat dilihat dalam Gambar 7. Berdasarkan hasil analisis data produksi dan jumlah alat tangkap yang ada di PPP Muncar dan PPN Pengambengan, maka di dapatkanlah hasil seperti gambar tersebut. Sehingga dapat dianggap bahwa penangkapan Ikan Lemuru di Perairan Selat Bali telah over fishing karena telah melebihi $\mathrm{f}$ optimum. Jumlah tangkap yang diperbolehkan adalah $80 \%$ dari MSY. Nilai MSY yang di dapatkan adalah 25107,32538 Ton pertahun,sehingga JTB dari penangkapan ikan lemuru adalah 25107,32538 x 80\% =20.085,86 Ton pertahun.

\section{PEMBAHASAN}

\section{Jumlah, Ukuran Kapal, dan Alat Bantu Penangkapan ikan}

Menurut Arif et.al., (2013), perikanan lemuru di perairan Selat Bali mengalami perkembangan dan peningkatan pesat setelah diperkenalkannya alat tangkap pukat cincin (purse seine) oleh Lembaga Penelitian Perikanan Laut (LPPL) yang sekarang menjadi BPPL pada tahun 1972. Sumberdaya ikan pelagis kecil menjadi komoditas utama di perairan Selat Bali, terutama ikan lemuru. Pesatnya perkembangan perikanan lemuru ini didukung oleh adanya pabrik-pabrik pengolahan, seperti pengalengan, pemindangan, tepung ikan, serta industri jasa penyimpanan ikan (cold storage). Perkembangan indsutri ikan lemuru menyebabkan meningkatnya jumlah kapal yang digunakan untuk menangkap ikan lemuru di perairan Selat Bali. Berdasarkan data yang didapatkan saat penelitian, dapat dilihat dinamika unit penangkapan ikan lemuru dengan menggunakan pukat cincin (purse seine) dengan armada kapal slerek yang terbuat dari kayu, dan pada umumnya terdiri dari dua kapal yang identik. Pada saat penangkapan ikan lemuru menjanjikan, maka jumlah alat tangkap yang digunakanpun akan bertambah.

Ukuran kapal yang digunakan terbagi menjadi dua jenis, yaitu 5-10 GT dan 10-30 GT. Di PPN Pengambengan, jenis kapal yang menggunakan purse seine hanya yang memiliki ukuran 10 - 30 GT. Berdasarkan hasil penelitian, ukuran kapal yang dominan di PPN Pengambengan adalah kapal yang berukuran 29/30 GT. Sementara di PPP Muncar jumlah purse seine lebih stabil. Jenis kapal yang dalam kategori 10 - 30 GT didominasi kapal dengan ukuran 28, 29, 30 GT. Sementara kategori 5-10 GT, didominasi oleh kapal berukuran 9 GT. Ukuran kapal akan menentukan kemampuan kapal untuk mengankut hasil tangkapan. Dengan ukuran kapal 30 GT maka muatan yang bisa di angkut oleh kapal \pm 10 ton untuk tiap kapal. Penangkapan ikan lemuru menggunakan dua kapal, sehingga dalam satu trip kapal dapat membawa muatan maksimal \pm 20 ton ikan. Semakin banyak ikan lemuru yang ditangkap, maka akan menyebabkan terjadinya growth over fishing yaitu terjadinya kelangkaan stok yang disebabkan oleh banyaknya ikan yang tertangkap. Menurut Diekert (2010), growth over fishing adalah kondisi dimana Ikan ditangkap sebelum mereka sempat tumbuh mencapai

\footnotetext{
${ }^{\circledR}$ Copyright by Management of Aquatic Resources (MAQUARES)
} 
ukuran dimana peningkatan lebih lanjut dari pertumbuhan akan mampu membuat seimbang dengan penyusutan stok yang diakibatkan oleh mortalitas alami (misalnya pemangsaan) pencegahan growth over fishing meliputi pembatasan upaya penangkapan, pengaturan ukuran mata jaring dan penutupan musim atau daerah penangkapan.

Peningkatan dan penurunan unit alat tangkap di dasari oleh berbagai macam faktor. Peluang ekonomi menjadi faktor yang menyebabkan terjadinya dinamika alat penangkapan ikan. Ikan lemuru merupakan komoditas ekonomis penting dalam industri perikanan Indonesia. Ikan lemuru yang digunakan untuk berbagai keperluan indsutri menyebabkan nilai ekonomis ikan lemuru semakin meningkat. Perikanan lemuru merupakan sebuah rantai ekonomi yang menjadi penggerak ekonomi di wilayah sekitar perairan Selat Bali. Ikan lemuru yang di tangkap oleh nelayan dapat dijual kepada pembeli lokal, indsutri, maupun keperluan ekspor. Berdasarkan hasil penelitian Merta et.al., (2000), jumlah kapal purse seine di wilayah perairan Selat Bali pada tahun 1974 adalah 10 unit, meningkat menjadi 70 pada tahun berikutnya, kemudian meningkat drastis pada tahun 1977 menjadi 193 unit, dan pada rentang tahun 1978 - 1997 bervariasi menjadi 200-280 unit.

Ukuran purse seine yang digunakan untuk kapal 10-30 GT memiliki panjang 180 depa dimana 1 depa $=$ 1,88 meter maka panjangnya mencapai \pm 338 meter dengan mesh size jaring sebesar 0.5 inchi. Penggunaan alat tangkap ini tidak sesuai dengan Peraturan Menteri Kelautan dan Perikanan no. 71 tahun 2016 tentang jalur penangkapan ikan dan penempatan alat penangkapan ikan di wilayah pengelolaan perikanan Negara Republik Indonesia. Dalam peraturan tersebut penggunaan purse seine harus dengan ketentuan mesh size $\geq 1$ inchi. Sementara alat tangkap yang digunakan nelayan mesh size ukuran 0,5 inchi. Berdasarkan hasil penelitian Satriya (2009), panjang jaring yang digunakan kapal $10-30$ GT periode tahun $1976-1984$ adalah \pm 140 meter, $1985-$ $1994 \pm 217$ meter, $1995-2000 \pm 322,5$ meter, $2001-2005 \pm 381,875$ meter.

PERMEN-KP No. 71 (2016), alat bantu penangkapan ikan terdiri dari rumpon, dan lampu. Rumpon merupakan alat bantu untuk mengumpulkan ikan dengan menggunakan berbagai bentuk dan jenis pemikat/atraktor dari benda padat yang berfungsi untuk memikat ikan agar berkumpul. Rumpon terdiri dari rumpon hanyut dan rumpon menetap. Lampu merupakan alat bantu untuk mengumpulkan ikan dengan menggunakan pemikat/atraktor berupa lampu atau cahaya yang berfungsi untuk memikat ikan agar berkumpul. Lampu dikategorikan menjadi lampu listrik dan lampu non listrik. Kapal purse seine dengan ukuran 10-30 GT di batasi untuk menggunakan lampu dengan daya maksimal 16.000 watt. Berdasarkan hasil penelitian yang dilakukan, nelayan lemuru yang berada di PP Muncar dan PPN Pengambengan,menggunakan alat bantu penangkapan ikan berupa lampu. Kapal yang berukuran 10 - 30 GT pada umumnya menggunakan alat bantu penangkapan berupa lampu sorot berdaya 700 - 1200 watt sebanyak 5-12 unit. Sementara untuk kapal yang berukuran 5-10 GT menggunakan 1-2 mesin, dengan kekuatan yang sama serta alat bantu lampu sebanyak 3-7 unit. Nelayan lemuru di PP Muncar dan PPN Pengambengan tidak melakukan pelanggaran terhadap peraturan terkait alat bantu penangkapan ikan karena daya maksimal lampu kapal hanya 14.400 watt, namun melanggar ukuran mesh size dari alat tangkap purse seine dengan ukuran 0,5 inchi. Berdasarkan hasil penelitian dari Merta et.al.,(2000), mesin kapal yang digunakan pada tahu 1995-2000 bervariasi antara 25 PK atau 30 PK, dengan jumlah mesin 4 unit, sedangkan lampu yang digunakan hanya sebatas untuk penerangan kapal.

Penangkapan ikan lemuru dengan menggunakan alat tangkap dengan mesh size 0,5 inchi dapat menyebabkan terjadinya recruitmen over fishing. Recruitmen over fishing merupakan kondisi dimana ikan hasil tangkapan dalam keadaan belum matang gonad, sehingga ikan belum memijah sudah tertangkap. Hal ini di dukung oleh Pauly dan Alan (1987), pengurangan melalui penangkapan terhadap suatu stok sedemikian rupa sehingga jumlah stok induk tidak cukup banyak untuk memproduksi telur yang kemudian menghasilkan rekrut terhadap stok yang sama. Pencegahan terhadap recruitment over fishing meliputi proteksi (misalnya melalui reservasi) terhadap sejumlah stok induk (parental stock, broodstock) yang memadai.

\section{Catch Per Unit Effort Penangkapan Ikan Lemuru}

Catch Per Unit Effort merupakan hasil dari pembagian produksi total dengan effort atau upaya penangkapan dengan satuan trip. Perhitungan CPUE pada umunya digunakan sebagai indeks kelimpahan relatif untuk pendugaan kelimpahan ikan model surplus produksi. Berdasarkan hasil yang didapatkan CPUE dari penangkapan ikan lemuru di perairan Selat Bali mengalami degradasi. Hal ini terlihat dari nilai CPUE yang setiap tahunnya menurun secara relatif. Nilai CPUE terendah adalah $0,378 /$ trip. Satu trip penangkapan memakan biaya $\operatorname{Rp} 4.500 .000$ - 5.500.000, apabila harga ikan lemuru per kilogram $\mathrm{Rp} 6.500$, maka nelayan hanya mendapatkan Rp 2.457.000. Nilai tersebut tidak sesuai dengan modal yang digunakan oleh nelayan. Sementara rata - rata CPUE adalah 3,43. Apabila dikonversikan maka pendapatan rata - rata dalam satu trip adalah Rp 22.295.000. Pendapatan tersebut yang menyebabkan banyaknya penangkapan ikan lemuru di perairan Selat Bali. Berdasarkan hasil penelitian Setyohadi (2009), CPUE dari penangkapan ikan lemuru mulai dari tahun 2000 mengalami penurunan yang signifikan, yaitu sebsar $6 \%$ per tahunnya. Oleh karena itu perlu dilakukan upaya pengelolaan agar tidak melebihi $M S Y$ karena sumber daya perikanan merupakan sumber daya yang sangat dinamis. Hal ini didukung oleh Susilo (2009), Dinamika stok ikan di suatu perairan laut bergantung kepada besarnya hasil tangkapan (yield) setiap tahunnya. Pada sisi lain besarnya hasil tangkapan dipengaruhi besarnya upaya penangkapan (effort). Besarnya upaya penangkapan di Indonesia (bahkan sebenarnya juga dimanapun) setiap tahun akan selalu berubah atau tidak tetap. Oleh karena itu besarnya stok ikan di suatu perairan juga bersifat dinamis. Hal ini juga mengakibatkan dinamika potensi lestari stok ikan (hasil tangkapan yang boleh

\footnotetext{
${ }^{\circledR}$ Copyright by Management of Aquatic Resources (MAQUARES)
} 
diambil tanpa merusak kelestarian sumberdaya). Pemanfaatan sumberdaya perikanan laut harus memenuhi persyaratan pemanfaatan sumberdaya alam yang berkelanjutan (sustainable natural resources use).

\section{MSY dan JTB Ikan Lemuru di Perairan Selat bali}

MSY merupakan sebuah pendugaan stok ikan yang berada di perairan dengan menggunakan penghitungan statistik. Berdasarkan hasil yang didapatkan, dapat dilihat penangkapan ikan lemuru di perairan Selat bali sudah berada di titik jenuh, yaitu dibawah ambang MSY dan jumlah upaya penangkapan melebihi $\mathrm{f}$ optimum. Upaya penangkapan yang berlebihan akan menyebabkan terus menurunnya stok ikan di alam, dan hasil penangkapan ikan lemuru. Hal ini didukung oleh Sparre dan Venema dalam Badrudin (2015), maksud dari pengkajian stok ikan adalah memberikan saran tentang pemanfaatan optimum sumberdaya hayati perairan seperti ikan dan udang. Sumberdaya hayati bersifat terbatas tetapi dapat memperbaharui dirinya. Pengkajian stok ikan dapat diartikan sebagai upaya pencarian tingkat pemanfaatan yang dalam jangka panjang memberikan hasil tangkapan maksimum perikanan dalam bentuk bobot.

Berdasarkan hasil dari penelitian didapatkan nilai MSY ( maximum sustainable yield) sebesar 25107,32538 ton. Berdasarkan hasil penelitian dari Merta et.al., (2000) nilai MSY pada tahun 1986 adalah 66.000 ton, kemudian pada tahun 1992 menurun menjadi 40.000 ton. Menurut Setyohadi (2009), pada tahun 2006 MSY penangkapan ikan lemuru adalah 23.447 ton.

Maximum Sustainable Yield (MSY) dari model Scheafer merupakan suatu bentuk pengelolaan perikanan yang bertujuan untuk pengelolaan perikanan yang baik. Namun,model dari Scheafer ini masih banyak memiliki kekurangan dalam pendugaan stock ikan. Model ini mengabaikan kondisi di lapangan berupa variabel - variabel penangkapan seperti iklim,cuaca,serta kondisi dari perairan tersebut. Hal ini diperkuat oleh Faudzi (2010), setelah ditemukan oleh Scheafer, MSY menjadi tujuan dalam pengelolaan perikanan. Dengan kata lain pembangunan perikanan diarahkan sedemikian rupa untuk mencapai nilai $M S Y$ ini. Namun, $M S Y$ ini memiliki beberapa kelemahan diantaranya :

1. Tidak bersifat stabil, karena perkiraan stok yang meleset sedikit saja bisa mengaruh ke penguasaan stok

2. Didasarkan pada konsep steady state ( kondisi ideal)

3. Mengabaikan interdependensi dari sumber daya

4. Sulit diterapkan pada kondisi dimana perikanan memiliki beragam jenis.

Jumlah tangkapan yang diperbolehkan (JTB) merupakan sebuah pembatasan penangkapan yang dilakukan oleh pemerintah untuk menjaga kelestarian stok sumber daya perikanan agar tidak terjadi kepunahan. Menurut Triyono (2013), jumlah tangkapan yang diperbolehkan adalah merupakan alih bahasa daripada "Total Allowable Catch (T.A.C.)" yang telah dibakukan dalam Undang-Undang Nomor 5 Tahun 1983 dan untuk keperluan sehari-hari dapat digunakan singkatan "J.T.B" (PP No. 15 Tahun 1984 tentang Pengelolaan Sumberdaya Hayati di Zona Ekonomi Eksklusif Indonesia, Bab I Pasal 1 huruf e). Nilai dari JTB adalah $80 \%$ dari $M S Y$ yang didapatkan. Angka ini merupakan rekomendasi dari Komisi Nasional Pengkajian Stok Ikan, yang kemudian ditetapkan oleh Menteri Kelautan dan Perikanan. JTB bertujuan untuk menjaga stok ikan dalam keadaan berkelanjutan. Nilai $80 \%$ ditetapkan karena dikhawatirkan data dari MSY yang didapatkan tidak akurat. Menurut Triyono (2013), tujuan utama JTB adalah mengatur jumlah penangkapan agar tidak melebihi daya dukung sumberdaya ikan, sehingga pemanfaatanya dapat lestari dan berkelanjutan. Sehingga pada perikanan lemuru nilai JTB di perairan Selat Bali adalah 20.085,86 Ton pertahun. Hal ini di dukung oleh Pudjiastuti (2016), dalam penangkapan sumber daya terdapat pilar keberlanjutan ( sustainability) yang penting untuk memastikan kekayaan laut Indonesia tidak habis hanya oleh satu generasi saja. Laut harus mampu menopang pembangunan nasional dan meningkatkan kualitas hidup bangsa Indonesia di masa sekarang maupun yang akan datang. Pemanfaatan sumber daya perikanan haarus sustainable dan viable agar Indonesia tidak saja dikenal dunia sebagai negara pemasok ikan, melainkan juga negara yang melindungi sumber daya kelautan dan perikanan.

\section{Pengelolaan Perikanan Lemuru di Perairan Selat Bali}

Perairan Selat Bali merupakan perairan antara Provinsi Jawa Timur, dan Provinsi Bali. Sehingga otonomi perairan ini di bawah naungan Pemerintah Provinsi Jawa Timur, dan Bali. Peraturan yang ditetapkan bertujuan untuk memastikan eksploitasi perikanan yang berkelanjutan. Manajemen perikanan lemuru memiliki sejarah yang panjang dalam perkembangannya di Indonesia. Pemrakarsaan yang pertama dilakukan pada tahun 1977 yang memastikan menejemen perikanan bersama antara pemerintah provinsi jawa timur, dengan provinsi bali. Penangkapan ikan lemuru yang semakin pesat menyebabkan kekhawatiran terjadinya kerusakan ekosistem. Sehingga pada tahun 1977 dikeluarkan Surat Keputusan Bersama (SKB) antara Gubernur Kepala Daerah Propinsi Daerah Tingkat I Jawa Timur dan Gubernur Kepala Daerah Propinsi Daerah Tingkat I Bali, yang kemudian diperbaharui pada tahun 1978 tentang penentuan jumlah purse seine yang boleh beroperasi di perairan Selat Bali. Kemudian pada tahu 1983 Direktorat Jendral Perikanan mengeluarkan Surat Keputusan Nomor EK230/83.2194/83 tertanggal 8 April 1983, untuk menaikkan jumlah purse seine yang boleh beroperasi di Selat Bali. Kemudian diperbarui lagi pada tahun 1984 dengan diadakan rapat koordinasi antara Gubernur Jawa Timur dan Gubernur Bali dan sebagai tindak lanjut pada tahun 1985 dikeluarkan Surat Keputusan Bersama (SKB) antara dua Pemerintah Daerah tersebut Nomor 7 tahun 1985/4 tahun 1985. Kemudian pada tahun 1992 SKB 
antara dua Gubernur ini diperbaharui lagi dengan Nomor 238 tahun 1992/674 tahun 1992 tertanggal 14 November 1992, dan selanjutnya pada tahun 1994 SKB tersebut ditindak lanjuti dengan SKB Kepala Dinas Perikanan Jawa Timur dan Kepala Dinas Perikanan Bali Nomor 10 tahun 1994/02 tahun 1994 tanggal 3 Pebruari 1994. Kemudian muncul peraturan terbaru pada tahun 2016, yaitu Peraturan Menteri Kelautan dan Perikanan Nomor 68 tentang Rencana Pengelolaan Perikanan Perikanan Ikan Lemuru di Wilayah Pengelolaan Perikanan Republik Indonesia. Peraturan tersebut menjadi acuan bagi Pemerintah Provinsi Jawa Timur dan Bali dalam membuat kebijakan.

\begin{tabular}{|c|c|}
\hline $\begin{array}{l}\text { SKB GUBERNUR KDH TK.1 JAWA TIMUR DAN } \\
\text { BALI TAHUN } 1986\end{array}$ & $\begin{array}{l}\text { SKB GUBERNUR KDH TK.1 JAWA TIMUR DAN } \\
\text { BALI TAHUN } 1992\end{array}$ \\
\hline $\begin{array}{l}\text { 1. Daerah operasi penangkapan ikan: } \\
\text { Daerah 1: perahu layar/tanpa motor } \\
08^{\circ} 40^{\prime} \mathrm{LS} 114^{\circ} 33^{\prime} \mathrm{BT} \\
08^{\circ} 13^{\prime} \mathrm{LS} 114^{\circ} 27^{\prime} \mathrm{BT} \\
08^{\circ} 30^{\prime} \mathrm{LS} 114^{\circ} 33^{\prime} \mathrm{BT} \\
\text { Daerah } 2 \text { : untuk kapal/perahu motor }\end{array}$ & $\begin{array}{l}\text { 1.Ditegaskan kembali kordinatnya : } \\
\text { Daerah 1: perahu layar/tanpa motor } \\
08^{\circ} 13^{\prime} \mathrm{LS} 114^{\circ} 23^{\prime} \mathrm{BT} \\
08^{\circ} 40^{\prime} \mathrm{LS} 114^{\circ} 27^{\prime} \mathrm{BT} \\
08^{\circ} 30^{\prime} \mathrm{LS} 114^{\circ} 53^{\prime} \mathrm{BT} \\
08^{\circ} 30^{\prime} \mathrm{LS} 114^{\circ} 33^{\prime} \mathrm{BT} \\
08^{\circ} 40^{\prime} \mathrm{LS} 114^{\circ} 33^{\prime} \mathrm{BT} \\
\text { Daerah } 2 \text { : untuk kapal/perahu motor }\end{array}$ \\
\hline $\begin{array}{l}\text { 2. Jumlah purse seine yang diijinkan } 273 \text { unit } \\
\text { (jatim }=190 \text { unit dan bali }=83 \text { unit })\end{array}$ & 2. Tetap \\
\hline $\begin{array}{l}\text { 3. Ukuran unit purse seine : } \\
\text { Panjang maks } 150 \mathrm{~m} \\
\text { Mata jaring : min } 1 \text { inchi }\end{array}$ & $\begin{array}{l}\text { 3. Ukuran unit purse seine : } \\
\text { Panjang maks } 300 \mathrm{~m} \\
\text { Dalam } 60 \mathrm{~m} \\
\text { Mata jaring : tetap }\end{array}$ \\
\hline $\begin{array}{l}\text { 4. Tanda pengenal } \\
\text { Warnas kasko : } \\
\text { Jatim = biru } \\
\text { Bali = putih } \\
\text { Tiang utama : abu-abu untuk jatim dan } \\
\text { merah untuk bali }\end{array}$ & $\begin{array}{l}\text { 4. Tanda pengenal } \\
\text { Warna kasko : bebas } \\
\text { Tiang utama : hijau tua untuk jatim dan merah untuk } \\
\text { bali } \\
\text { Bendera segitiga sama kaki } \\
\text { Ukuran atas : } 0,5 \mathrm{~m} \text {; kaki : } 1,0 \mathrm{~m} \text {; danw arna sesuai } \\
\text { warna tiang utama }\end{array}$ \\
\hline $\begin{array}{l}\text { 5. Pengawasan pemda tingkat } 2 \text { setempat } \\
\text { berkordinasi dengan unsur satgaskamla }\end{array}$ & 5. Pengawasa tetap, ditambah agar lebih ditingkatkan \\
\hline $\begin{array}{l}\text { 6. Pemasaran ikan hasil tangkapan harus di } \\
\text { jual di tpi dimana ijin diperoleh }\end{array}$ & $\begin{array}{l}\text { 6. Pemasaran } \\
\text { Tetap, ditambah antar kud mina kedua daerah dapat } \\
\text { mengadakan kerjasama }\end{array}$ \\
\hline $\begin{array}{l}\text { 7. Pertemuan rutin dan berkala minimal } 6 \\
\text { bulan sekali untuk saling tukar informasi }\end{array}$ & 7. Tetap \\
\hline $\begin{array}{l}\text { 8. Tanpa persetujuan masing-masing dewan } \\
\text { tingkat } 1 \text { dan mendagri }\end{array}$ & $\begin{array}{l}\text { 8. Dengan persetujuan masing-masing dewan tingkat } \\
1 \text { dan mendagri }\end{array}$ \\
\hline
\end{tabular}

Tabel 2. Perbandingan SKB Pemerintah Provinsi Jatim dan Bali Tahun 1985 \& 1992

Peraturan tersebut kemudian menimbulkan gejolak di masyarakat. Nelayan yang umumnya memiliki ilmu pengetahuan yang terbatas, tentunya menolak kebijakan yang dikeluarkan oleh pemerintah, terlebih lagi peraturan yang membatasi mata pencaharian utama mereka. Kurangnya sosialisasi dari pemerintah sebelum menerapkan program merupakan faktor ditolaknya peraturan oleh nelayan. Pemerintah sebagai stake holder sebelum mengeluarkan suatu kebijakan sebaiknya mengumpulkan para stake holder perikanan lemuru yang terdiri dari pemerintah, akademisi, penyuluh, penjaga keamanan, nelayan, pengusaha cold storage, pengusaha pengolahan ikan, serta pemilik kapal untuk melakukan sosialisasi, dan konsolidasi agar tidak terjadi penolakan terhadap peraturan yang telah di tetapkan oleh pemerintah. Selain itu kebijakan yang dikeluarkan oleh pemerintah harus diarahkan kepada kesejahteraan masyarakat. Hal ini didukung oleh Riyadi (2004), arah kebijakan pengelolaan dan pembangunan perikanan dan kelautan harus diarahkan kepada kesejahteraan rakyat, penciptaan lapangan kerja dan pertumbuhan ekonomi.

Penolakan dari masyarakat sering kali disebabkan oleh persepsi masyarakat yang menganggap bahwa sumber daya perikanan merupakan sumber daya yang tak dapat habis dan dapat ditangkap terus menerus tanpa mengkhawatirkan kondisi stok ikan di alam. Sehingga sumber daya perikanan sering disebut sebagai sumber daya open access. Karakteristik sumber daya yang merupakan open access ini menyebabkan anggapan bahwa sumber daya perikanan adalah milik semua orang tanpa terkecuali (common property). Hal ini di dukung oleh Fauzi (2010), perikanan memiliki karakteristik yang berbeda dengan sumberdaya lain,karena sumberdaya ini berdasarkan doktrin res nullius yang dalam bahasa latin berarti objek yang seharusnya bisa dimiliki namun tidak 
bisa dimiliki oleh individu. Berdasarkan kaidah inilah yang menyebabkan sumberdaya perikanan merupakan sumberdaya common property.

Kemudian dikeluarkan peraturan terbaru pada tahun 2016, yaitu Peraturan Menteri Kelautan dan Perikanan Nomor 68 tentang Rencana Pengelolaan Perikanan Perikanan Ikan Lemuru di Wilayah Pengelolaan Perikanan Republik Indonesia. Peraturan tersebut menjadi acuan bagi Pemerintah Provinsi Jawa Timur dan Bali dalam membuat kebijakan.

Produksi perikanan lemuru di Selat Bali mengalami paceklik dari bulan September 2016 sampai pada bulan Mei 2017. Data ini di dapatkan dari PPP Muncar, serta PPN Pengambengan, serta wawancara dengan nelayan sekitar. Berdasarkan hasil wawancara, menurut nelayan terjadinya paceklik disebabkan oleh tiga hal, yaitu terjadinya kepunahan / kelangkaan ikan karena nelayan terlalu banyak menangkap ikan lemuru, dan tidak selektif dalam penangkapan. Pada saat musim penangkapan, nelayan di PPP Muncar dan Pengambengan dapat melakukan dua trip penangkapan dalam satu hari. Nelayan pada umumnya ingin mengeruk keuntungan sebesarbesarnya ketika musim lemuru, meskipun mereka mengetahui dampaknya adalah berkurangnya produksi lemuru pada musim berikutnya, atau bahkan terjadi paceklik. Oleh karena itu perlu diberlakukan regulasi yang tegas untuk membatasi trip pada saat musim tangkap. Hal ini di dukung oleh Utami et.al (2012), sumberdaya perikanan tersedia melimpah dan mempunyai kemampuan untuk pulih kembali, namun tanpa adanya pengawasan dan pengelolaan terhadap usaha penangkapan yang berlangsung secara terus menerus, dapat menyebabkan terjadinya over fishing dan penurunan hasil tangkapan di suatu perairan atau bahkan di beberapa daerah penangkapan.

Kedua, ikan lemuru yang ada, beruaya menuju rumpon nelayan yang digunakan untuk menangkap ikan tuna di perairan Samudera Hindia. Menurut nelayan penangkap tuna, di areal rumpon tersebut terdapat banyak ikan lemuru. Hal ini sesuai dengan penelitian dari Subani (1972) dalam Merta et al., (2000), rumpon berfungsi sebagai pengumpul kawanan ikan. Pada prinsipnya digunakan untuk mempermudah ikan ditangkap, sehingga banyak ikan - ikan pelagis kecil yang berada di sekitar rumpon.

Ketiga, terjadinya pencemaran perairan Selat Bali yang disebabkan oleh industri - industri di sekitar daerah Kabupaten Banyuwangi dan Jembrana. Meningkatnya produksi ikan lemuru setelah diperkenalkan alat tangkap purse seine menyebabkan industri perikanan ikan meningkat pesat di wilayah Kabupaten Banyuwangi dan Jembrana. Banyaknya pabrik menyebabkan meningkatnya permintaan ikan. Banyaknya produksi ikan menyebabkan berjalannya kegiatan industri,sehingga limbah industri yang dihasilkanpun meningkat. Pada umumnya industri perikanan berlokasi disekitar pelabuhan perikanan ataupun di daerah pesisir. Lokasi pabrik yang berada di sekitar pesisir,menyebabkan pabrik melakukan pembuangan limbah secara massal dan massif, ke wilayah perairan. Pencemaran perairan juga diberburuk dengan tingginya transportasi laut yaitu penyebrangan Jawa-Bali. Tingginya transportasi laut menyebabkan semakin banyak limbah dari transportasi laut yang masuk kedalam perairan. Hal ini didukung oleh Yusuf, dan Gentur (2004), adanya kegiatan industri, pemukiman, dan tambak yang tersebar di pesisir dan hilir sungai memberikan kontribusi terhadap menurunnya kualitas air. Bahan pencemar dan polutan menyebabkan menurunnya kualitas air sehingga membahayakan bagi organisme perairan. Pencemaran yang terjadi akan menyebabkan perubahan homeostatis dari biota, sehingga biota akan ber-ruaya untuk mencari lingkungan yang sesuai.

Sementara menurut Balai Penelitian dan Observasi Laut, paceklik perikanan lemuru yang terjadi di perairan Selat Bali merupakan dampak nyata dari perubahan lingkungan global. Perubahan iklim yang terjadi menyebabkan naiknya suhu permukaan air laut,sehingga Ikan Lemuru masih berada di posisi perairan dalam.Sementara itu,alat tangkap yang digunakan oleh nelayan, belum dapat menjangkau bagian laut yang lebih dalam. Iklim yang tidak menentu menyebabkan terjadinya perubahan homeostatis pada Ikan Lemuru, dan merubah tingkah laku serta pola migrasi Ikan Lemuru. Hal ini di dukung oleh Urfan et al., (2013), pada awal musim timur hasil tangkapan lemuru sangat rendah,dan akan meningkat pada akhir musim timur, namun pada musim barat di awal musim hasil tangkapan lemuru sangat tinggi dan semakin rendah pada akhir musim barat. Gambaran tersebut sesuai dengan pendapat Subani (1971) dalam Indrawati (2000), yang menyatakan bahwa ikan lemuru di perairan Selat Bali dikenal sebagai ikan musiman karena ikan ini muncul pada musim-musim tertentu saja. Ikan lemuru mulai muncul pada saat musim timur, mula-mula dalam jumlah kecil kemudian dalam jumlah besar dan semakin banyak serta mencapai puncaknya pada bulan-bulan di awal musim barat.

\section{KESIMPULAN}

Jumlah kapal yang digunakan untuk penangkapan ikan lemuru saat ini adalah 326 armada dengan ukuran 10-30 GT yang didominasi oleh kapal ukuran 29/30 GT . Jumlah kapal 10 - 30 GT di Muncar 190 unit, sedangkan di Pengambengan 136 unit. Alat tangkap yang digunakan adalah purse seine dengan jumlah 326 dengan panjang 180 depa ( \pm 338 meter) dan mesh size 0,5 inchi, dengan rata - rata kekuatan mesin $120-240$ PK, lampu 700 - 1200 watt sebanyak 5 - 12 unit / kapal. Nilai CPUE terendah adalah 0,378 ton/trip, dengan rata - rata 3,43ton/ trip. Nilai $M S Y$ yang didapatkan sebesar 25107,32 ton/tahun, sementara nilai JTB (Jumlah Tangkapan Diperbolehkan) adalah 20.085,86 ton per tahun. Perairan Selat Bali berada dalam otonomi Pemerintah Provinsi Jawa Timur, dan Provinsi Bali. Sehingga pada tahun 1977 dikeluarkan Surat Keputusan Bersama Gubernur Jawa Timur, dan Gubernur Bali, untuk mengatur sistem penangkapan ikan di Perairan Selat 
Bali. Surat Keputusan Bersama ini diperbarui beberapa kali, kemudian dikeluarkan Peraturan Menteri Kelautan Perikanan dan Kelautan Nomor 68 Tahun 2016 tentang RPP Ikan Lemuru di WPP NRI.

\section{UCAPAN TERIMAKASIH}

Ucapan terimakasih ditujukan kepada Dra. Niniek Widyorini MS yang telah meberikan saran dan kritik yang sangat bermanfaat bagi penulis. Kepada semua pihak yang telah membantu sehingga penulisa dapat menyelesaikan artikel ini.

\section{DAFTAR PUSTAKA}

Badrudin. 2015. Analisis Data Catch \& Effort untuk Pendugaan MSY. Paper Of Indonesia Marine And Climate Support Project.USAID \& KKP.

Badan Pusat Statistik Kabupaten Banyuwangi. 2012. Banyuwangi Dalam Angka 2012. Banyuwangi.

Diekert, F K. 2010. Growth Overfishing. Paper on International Institute for Fisheries Economics and Tradings Conference. Montpellier.

Dinas Kelautan dan Perikanan Kabupaten Banyuwangi. 2003. Laporan Akhir Tahun 2003. Banyuwangi.

Dinas Kelautan dan Perikanan Provinsi Bali. 2000. Laporan Akhir Tahun 2000. Denpasar.

Dinas Kelautan dan Perikanan Provinsi Jawa Timur. 2000. Laporan Akhir Tahun 2000. Surabaya.

Fauzi, A. 2010. Ekonomi Perikanan : Teori, Kebijakan,dan Pengelolaan. Gramedia Pustaka Utama. Hal 19. Jakarta.

Ghofar A; CP Mathews; IGS Merta; S Salim. 2000. Incorporating The Southern Oscillation Indices To The Management Model Of The Bali Strait Sardinella Fishery. Workshop Fishery and Management of Bali Sardinella (Sardinella lemuru) in Bali Strait. Report of the Indonesia / FAO / Noorway Government Cooperative Programe Papers Presented At The Workshop On The Fishery And Management Of Bali Sardinella (Sardinella Lemuru) In Bali Strait. GCP / INT/ 648/ Nor Fr F-3.

Indrawati A. 2000. Studi Tentang Hubungan Suhu Permukaan Laut Hasil Pengukuran Satelit terhadap Hasil Tangkapan Ikan Lemuru (Sardinella lemuru Bleeker 1853) di Selat Bali (Tesis). Bogor: Program Pascasarjana, Institut Pertanian Bogor.

Irianto HE dan Indroyono S. 2007. Dukungan Teknologi Penyediaan Produk Perikanan. Badan Riset Kelautan dan Perikanan. Seminar Nasional Pangan Sedunia. Bogor.

Komisi Nasional Pengkajian Stok Sumber Daya Ikan Laut. 2014. Potensi Perikanan Tangkap Indonesia. Laporan Kerja Akhir Tahun. Jakarta.

Marita, IJ; Asriyanto; Purwanto. 2005. Alternatif Pengelolaan Perikanan Lemuru di Selat Bali (The Alternative Management for The Bali Strait Sardine (Lemuru) Fishery).UNDIP Repository.Semarang.

Merta IGS; K. Widana; Yunizal; R. Basuki. 2000. Status of the lemuru fishery in Bali Strait Its development and prospects.Workshop Fishery and Management of Bali Sardinella (Sardinella lemuru) in Bali Strait. Report of the Indonesia / FAO / Noorway Government Cooperative Programe Papers Presented At The Workshop On The Fishery And Management Of Bali Sardinella (Sardinella Lemuru) In Bali Strait. GCP / INT/ 648/ Nor Fr F-3.

Pasisingi, N. 2011. Model Produksi Surplus untuk Pengelolaan Sumberdaya Rajungan (Portunus pelagicus) di Teluk Banten, Kabupaten Serang, Provinsi Banten. Jurnal Ilmu-Ilmu Perairan dan Perikanan.Vol 17.IPB.

Pauly, D; Alan R.L. 1987. Ecology Of Tropical Fisheries. Academic Press. London.

Perdana, TW. 2012. Produktivitas Perikanan Lemuru di Pelabuhan Perikanan Pantai Muncar, Banyuwangi, Jawa Timur. Jurnal Ilmu-Ilmu Perairan dan Perikanan. Vol 19. IPB.

Pelabuhan Perikanan Nusantaran Pengambengan. 2010. Laporan Pertanggung Jawaban PPN Pengambengan.

Peraturan Mentri Kelautan dan Perikanan Nomor 68 Tahun 2016 Tentang Rencana Pengelolaan Perikanan Ikan Lemuru di Wilayah Pengelolaan Perikanan Negara Republik Indonesia.

Saputra, SW. 2009. Dinamika Populasi Ikan Berbasis Riset. Badan Penerbit Universitas Diponegoro. Semarang.

Satriya, INB. 2009. Stock Assessment and Dynamics of the Sardinella lemuru (Clupeidae) Resources in the Bali Straits. Seminar Nasional Teori dan Aplikasi Teknologi Kelautan.

Setyohadi, D. 2009. Studi Potensi dan Dinamika Stok Ikan Lemuru (Sardinella Lemuru) Di Selat Bali Serta Alternatif Penangkapannya. Jurnal Ilmiah Perikanan. Vol 11. Unibraw.

Setyohadi, D; D.Sutipto; D.G.R.Wiadnya. 1998. Dinamika populasi ikan lemuru (Sardinella lemuru) serta alternatif pengelolaannya. Jurnal Penelitian Ilmu-ilmu Hayati. Lembaga Penelitian Unibraw. Vol 10. Unibraw.

Pudjiastuti, S. 2016. Pemberantasan IUU Fishing : Menegakkan Kedaulatan dan Menjaga Keberlanjutan untuk Kesejahteraan Bangsa Indonesia. Pidato Penganugerahan Doktor HC. UNDIP.

Susilo, SB. 2009. Kondisi Stok Ikan Perairan Pantai Selatan Jawa Barat. Jurnal Ilmu-Ilmu Perairan dan Perikanan Indonesia, Jilid 16, Nomor 1: 39-46

Triyono, H. 2013. Metode Penetapan Jumlah Tangkapan Yang Diperbolehkan (JTB) Untuk Berbagai Jenis Sumberdaya Ikan Di WPP-NRI. Fisheries Resources Laboratory. Jakarta Fisheries Univ.

Umar, H. 2004. Riset Sumberdaya Manusia. Gramedia Pustaka Utama; Jakarta. 
Urfan, R; Max RM; Agus H. 2013. Analisa Sebaran Tangkapan Ikan Lemuru (Sardinella lemuru) Berdasarkan Data Satelit Suhu Permukaan Laut dan Klorofil-a di Perairan Selat Bali. Maquares Vol 2. UNDIP.

Utami, Diani P; Iwang, G; Sriati. 2012. Analisis Bioekonomi Penangkapan Ikan Layur Di Perairan Parigi Kabupaten Ciamis. Jurnal Perikanan dan Kelautan.Vol 3. Unpad.

Wudianto. 2001. Karakteristik Gerombolan Ikan Lemuru (Sardinella lemuru Bleeker 1853) di Perairan Selat Bali. Jurnal Penangkapan Perikanan Indonesia. Vol 7

Wujdi, A; Suwarso;Wudianto. 2012. Beberapa Parameter Populasi Ikan Lemuru (Sardinella lemuru, Bleeker 1853) di Perairan Selat Bali. Bawal. Vol 5. 